\title{
A brave new world: integrating well-being and conservation
}

\author{
Kelly Biedenweg ${ }^{1}$ and Nicole D. Gross-Camp ${ }^{2,3}$
}

ABSTRACT. Aldous Huxley's Brave New World promised an enduring, happy society as long as it followed rigid, scientifically defined social rules. Just as this supposed utopia led to immense human suffering as people were constrained to predefined societal roles with limited opportunity for self-expression, conservation initiatives that impose predefined conceptions of well-being onto the poor and politically disadvantaged will meet with tenuous success. In this special feature, we provide a selection of studies that address the how and why of integrating human well-being into conservation practice focusing predominantly on local perspectives. Authors focus on how engagement with local populations is driven, implicitly or explicitly, by the pursuit of a more just conservation and recognition of local voices in deciding their fate.

Key Words: conservation; justice; well-being

\section{INTRODUCTION}

In 1931 Aldous Huxley invented a world where science was used to maximize people's happiness and comfort. Societal roles were defined quite literally at conception, eliminating the anxiety of making decisions. Happiness was pursued above all other goals through "objective" science with nonconformists being cast away to islands to live as freethinking "savages." Despite the promises of this "Brave New World," all was not well. Huxley described a deeply disturbing society that operated largely on numb autopilot disconnected from the natural world. Ironically, it was the pursuit of a rigidly defined "happiness," Huxley alluded, which lead to unhappiness and threatened the long-term stability of his utopian world.

The field of conservation has similarly focused on rigid scientific goals in its pursuit of conservation outcomes. Some early ideals of conservation saw protected areas as wild and pristine landscapes whose natural resources were strictly managed. In this vision, society's greatest benefits would come from protected natural resources, which was commonly obtained by excluding lower classes from living within or engaging in traditional extractive activities (Brockington 2004). Yet society's values often differ from those making management decisions. Although managers may prioritize pristine landscapes, other members of society may not see the world in the duality of nature vs. human, or they may prioritize traditional uses over exclusion. Thus, the promised generalized benefits to society from exclusionary-based conservation strategies may similarly threaten the long-term satisfaction and well-being of humanity.

The publication of the Millennium Ecosystem Assessment (2005) highlighted the intricate and diverse links between human wellbeing and the environment. Of course, the linkages between human well-being and nature depend on how one defines wellbeing (Leisher et al. 2013, Smith et al. 2013, Agarwala et al. 2014), and definitions encompass dozens of study agendas, ranging from public health to psychology to development studies. Despite this diversity of thought, it is broadly agreed that human well-being comprises at least three dimensions: material (such as income, livelihoods, and housing), relational (social and political processes that determine how people meet their needs and achieve their goals), and subjective (individual, social, and cultural norms that influence people's preferences and behavior; Gough and McGregor 2007).
The emergence of well-being into the conservation dialogue has largely stemmed from development studies, and in particular the focus on poverty as a proxy to the lack of well-being. Since the 1980 s, social approaches in conservation included alternative livelihood strategies, ecotourism, or direct payments for ecosystem services to reduce dependence of local communities on natural resources. Despite some successes, these approaches have generally failed to reconcile the priorities of local and marginalized groups with conservation objectives (Newmark and Hough 2000). Programs and research approaches that use singular definitions of well-being overlook important social impacts and dynamics, such as tenure security, that can ultimately backfire on conservation effectiveness. Just as development studies are responding to the inability of financial indicators alone to describe one's state of poverty (Imran et al. 2014), conservation initiatives that focus on monetary benefits are increasingly scrutinized for their lack of attention to broader, nonpecuniary aspects of well-being such as cultural traditions, personal identity, and sense of place (Pascual et al. 2014, Calvet-Mir et al. 2015, Masterson et al. 2017).

The inclusion of human well-being in conservation dialogues is driven by a discourse that without meeting the needs and gaining the support of the people that conservation interventions affect, those interventions will inevitably fail. This view, however, has been highly disputed with some work showing that conservation initiatives can still succeed (ecologically) despite severe impacts on people's well-being (Brockington 2004). Moreover, social scientific research has found that exclusive conservation strategies have often resulted in severe negative impacts on people who are already poor and politically disadvantaged (West et al. 2006, McKinnon et al. 2016). Such impacts inform a broad moral stance that ignoring the well-being of people affected by conservation is unfair, especially given the power asymmetries often involved (Lele et al. 2010, Martin et al. 2015).

In addition to the "inevitable failure" argument, a global expansion of environmental justice to consider diverse drivers of well-being, including process and recognition (Martin et al. 2016), has put pressure on conservationists to move beyond a focus on monetary or material well-being. This expanded consideration of social justice within conservation policy and strategies would include the distribution of costs and benefits, local participation in decision making, and a recognition of people's distinct cultures 
and identities as affected by conservation interventions (ZafraCalvo et al. 2017). Through this vision, a more promising Brave New World would emerge in which the multivalent nature of wellbeing is embraced and the ecological and social trade-offs associated with conservation openly deliberated and negotiated (McShane et al. 2011).

\section{APPROACHING A BRAVE NEW WORLD}

In this special feature, we present work focused on integrating human well-being within the context of conservation initiatives. Our objective is to describe and synthesize emerging efforts while highlighting practical methods. The contributions to this special feature take two general forms: research papers and insights. Both are founded in rigorous field-based methods, yet one places greater attention on empirical testing of a research question (research papers) while the other places emphasis on practical guidelines based on lessons learned from extensive experience (insights). Several of the papers describe different ways of operationalizing human well-being so that researchers and practitioners can better monitor and plan for locally relevant wellbeing outcomes. Other papers describe how well-being metrics have been used to monitor, evaluate, or plan conservationoriented activities. All identify the challenges associated with integrating diverse goals and navigating political contexts.

Researchers in the field are driven to seek a balance between conservation and human well-being for a number of reasons, although most are ultimately influenced by an ideal of a more socially just conservation. In some cases, existing policy objectives lay the mandate for such considerations. For example, the Puget Sound Partnership is a U.S. state agency that was developed with the statutory goals of restoring the Puget Sound watershed and protecting the quality of life and health of its residents, thus laying the framework for assessing the attainment of these social and ecological goals (Biedenweg et al. 2017). Similarly, the REDD+ framework associated with the global climate change agreements outlines a set of social and environmental safeguards for REDD+ initiatives (Duchelle et al. 2017). In other cases, the researcher's interest alone in environmental justice informed the consideration of local perspectives when developing well-being indicators (Caillon et. al. 2017, McCarter et al. 2018), defining well-being to inform the design of future conservation initiatives and evaluations (Gross-Camp 2017, Beauchamp et al. 2018), and assessing the influence of conservation practices on human communities (Gross-Camp 2017, Rodriguez 2017, Cooper and Kainer 2018). Although the institutional drivers for integrating human well-being and conservation differed, all articles had the same outcome: identifying dimensions of well-being as defined by those being influenced by conservation.

Six of the contributed papers focus on defining well-being within the context of local populations (Biedenweg et al. 2017, Caillon et al. 2017, Gross-Camp 2017, Beauchamp et al. 2018, McCarter et al. 2018, Woodhouse and McCabe 2018), highlighting some heterogeneity across demographics and geographies. In addition to describing local conceptions of well-being, the studies provide diverse examples for how practitioners and researchers can elicit such definitions. Gross-Camp (2017) engaged local communities in Tanzania using participatory video to explore and ultimately define the dimensions of well-being important to them, culminating in the production of a film. Wali et al. (2017) worked with communities in the Peruvian Amazon for over 17 years with a variety of tools, including community-based asset mapping. Rodriguez (2017) analyzed the results of Venezuelan community members' life plans and traditional ecological knowledge reports to identify what was important to them. The selection of a wellbeing elicitation tool has an impact on the type of information provided, e.g., indicators, visualizations, or oral stories. Although such diversity of resulting data types provides multiple angles from which to understand a topic, it can also be difficult to integrate with biophysical data (if the separation of human wellbeing and nature is a prominent part of the dialogue) to assess inevitable trade-offs. Caillon et al. (2017) and McCarter et al. (2018) respond to this conundrum by describing that biocultural indicators, elicited from locally appropriate citizens, inherently incorporates the social-ecological trade-offs as they are integrated metrics.

In addition to the different ways of eliciting definitions of wellbeing, contributing authors provide tools for monitoring and evaluating changes in well-being associated with conservation initiatives. Biedenweg et al. (2017), Caillon et al. (2017), and McCarter et al. (2018) emphasize the use of indicators that can be measured at different periods in time across different stakeholder groups. Anaya and Espírito-Santo (2017) discuss the use of mental model mapping for a retrospective analysis of wellbeing impacts in Brazilian communities. In a more traditional research design, Gross-Camp (2017) uses semistructured surveys within natural experiments to evaluate the trade-offs between resource management activities and perceptions of well-being. And Wali et al. (2017) and Rodriguez (2017) demonstrate that monitoring and evaluation are evolving processes that must match the dynamics of communities; therefore participatory, collaborative tools that allow for adaptive integration of wellbeing and conservation can often be particularly effective. Dawson et al. (2017) concur, emphasizing that subjective experiences must always be part of the measurement of well-being because conceptualizations that do not fully capture the dynamism of well-being (such as indicators) may paint a limited picture of trade-offs and create misleading implications for addressing them.

In addition to a focus on the definition and evaluation of wellbeing associated with conservation, five of the contributed papers specifically tested how sustainable-use-oriented conservation interventions impact local well-being. Following the growing trend on this topic, these studies found variable levels of influence, depending on how well-being was defined and the details of the initiative. Gross-Camp (2017) found that community forestry in Tanzania had limited impact on household wealth, but that community members still supported the initiative because of greater governance over and pride in their natural resources. In Brazilian extractive reserves, communities sold the rights to extract their timber, engaging in very little of the actual activity (Cooper and Kainer 2018). The authors found both positive (social and financial) and negative (environmental and governance) impacts of these projects, with variations in perceptions of these across gender. Last, in assessing subnational REDD+ initiatives in six countries across Latin America, Africa, and Asia, Duchelle et al. (2017) found that interventions focused solely on disincentives (such as fines) negatively impacted perceived tenure security and subjective well-being whereas those 
that incorporated incentives (such as payment for ecosystem services) buffered the negative subjective well-being outcomes.

\section{SUMMARY}

Human well-being itself may have little policy traction with the conservation dialogue, but increasing conversations about the multiple feedbacks of coupled social-ecological systems and the pressure of policies associated with social justice render its consideration crucial (Dawson et al. 2017). In this special feature, authors focused on locally conceived definitions of well-being and the implications of these definitions for a conservation intervention or outcome. Authors provided detailed accounts of exploring nonmaterial aspects of human well-being and integrating these conceptualizations in conservation practice, highlighting the need to embrace a diversity of definitions, while simultaneously allowing the definitions to be fluid. The authors' research designs were largely participatory and grounded, implicitly or explicitly, in a paradigm focused on giving voice to the less powerful. This focus emerged from a recognition that how we define well-being influences our government policies, conservation practice, and ultimately human flourishing. Many of us hold a vision of a Brave New World in which science is more broadly representative of people's world views, and conservation decisions are driven through deliberative and inclusive processes, which result in a more just and equitable world for people and planet, in short, promoting well-being that is comprehensive, strong, and sustainable.

Responses to this article can be read online at: http://www.ecologyandsociety.org/issues/responses. php/9977

\section{Acknowledgments:}

The authors thank collaborating authors in the special feature for their feedback on this introduction.

\section{LITERATURE CITED}

Agarwala, M., G. Atkinson, B. Palmer Fry, K. Homewood, S. Mourato, J. M. Rowcliffe, G. Wallace, and E. J. Milner-Gulland. 2014. Assessing the relationship between human well-being and ecosystem services: a review of frameworks. Conservation and Society 12(4):437-449. http://dx.doi.org/10.4103/0972-4923.155592

Anaya, F. C., and M. M. Espírito-Santo. 2018. Protected areas and territorial exclusion of traditional communities: analyzing the social impacts of environmental compensation strategies in Brazil. Ecology and Society 23(1):8. http://dx.doi.org/10.5751/ ES-09850-230108

Beauchamp, E., E. Woodhouse, T. Clements, and E. J. MilnerGulland. 2018. "Living a good life": conceptualizations of wellbeing in a conservation context in Cambodia. Ecology and Society 23(2):28. http://dx.doi.org/10.5751/ES-10049-230228

Biedenweg, K., H. Harguth, and K. Stiles. 2017. The science and politics of human well-being: a case study in cocreating indicators for Puget Sound restoration. Ecology and Society 22(3):11. http:// dx.doi.org/10.5751/ES-09424-220311
Brockington, D. 2004. Community conservation, inequality, and injustice: myths of power in protected area management. Conservation and Society 2:411-432.

Caillon, S., G. Cullman, B. Verschuuren, and E. J. Sterling. 2017. Moving beyond the human-nature dichotomy through biocultural approaches: including ecological well-being in resilience indicators. Ecology and Society 22(4):27. http://dx.doi. org/10.5751/ES-09746-220427

Calvet-Mir, L., E. Corbera, A. Martin, J. Fisher, and N. GrossCamp. 2015. Payments for ecosystem services in the tropics: a closer look at effectiveness and equity. Current Opinion in Environmental Sustainability 14:150-162. http://dx.doi.org/10.1016/ j.cosust.2015.06.001

Cooper, N. A., and K. A. Kainer. 2018. To log or not to log: local perceptions of timber management and implications for wellbeing within a sustainable-use protected area. Ecology and Society 23(2):4. http://dx.doi.org/10.5751/ES-09995-230204

Dawson, N. M., K. Grogan, A. Martin, O. Mertz, M. Pasgaard, and L. V. Rasmussen. 2017. Environmental justice research shows the importance of social feedbacks in ecosystem service tradeoffs. Ecology and Society 22(3):12. http://dx.doi.org/10.5751/ ES-09481-220312

Duchelle, A. E., C. de Sassi, P. Jagger, M. Cromberg, A. M. Larson, W. D. Sunderlin, S. S. Atmadja, I. A. P. Resosudarmo, and C. D. Pratama. 2017. Balancing carrots and sticks in REDD+: implications for social safeguards. Ecology and Society 22(3):2. http://dx.doi.org/10.5751/ES-09334-220302

Gough, I., and J. A. McGregor. 2007. Wellbeing in developing countries: from theory to research. Cambridge University Press, Cambridge, UK. http://dx.doi.org/10.1017/CBO9780511488986

Gross-Camp, N. 2017. Tanzania's community forests: their impact on human well-being and persistence in spite of the lack of benefit. Ecology and Society 22(1):37. http://dx.doi. org/10.5751/ES-09124-220137

Imran, S., K. Alam, and N. Beaumont. 2014. Reinterpreting the definition of sustainable development for a more ecocentric reorientation. Sustainable Development 22:134-144. http://dx.doi. org/10.1002/sd.537

Leisher, C., L. H. Samber, P. van Beukering, and M. Sanjayan. 2013. Focal areas for measuring the human well-being impacts of a conservation initiative. Sustainability 5:997-1010. http://dx.doi. org/10.3390/su5030997

Lele, S., P. Wilshusen, D. Brockington, R. Seidler, and K. Bawa. 2010. Beyond exclusion: alternative approaches to biodiversity conservation in the developing tropics. Current Opinion in Environmental Sustainability 2:94-100. http://dx.doi.org/10.1016/ j.cosust.2010.03.006

Martin, A., A. Akol, and N. Gross-Camp. 2015. Towards an explicit framing of the social impacts of conservation. Conservation and Society 13:166-178. http://dx.doi. org/10.4103/0972-4923.164200

Martin, A., B. Coolsaet, E. Corbera, N. M. Dawson, J. A. Fraser, I. Lehman, and I. Rodriguez. 2016. Justice and conservation: the need to incorporate recognition. Biological Conservation 197:254-261. http://dx.doi.org/10.1016/j.biocon.2016.03.021 
Masterson, V. A., R. C. Stedman, J. Enqvist, M. Tengö, M. Giusti, D. Wahl, and U. Svedin. 2017. The contribution of sense of place to social-ecological systems research: a review and research agenda. Ecology and Society 22(1):49. http://dx.doi.org/10.5751/ ES-08872-220149

McCarter, J., E. J. Sterling, S. D. Jupiter, G. D. Cullman, S. Albert, M. Basi, E. Betley, D. Boseto, E. S. Bulehite, R. Harron, P. S. Holland, N. Horning, A. Hughes, N. Jino, C. Malone, S. Mauli, B. Pae, R. Papae, F. Rence, O. Revo, E. Taqala, M. Taqu, H. Woltz, and C. E. Filardi. 2018. Biocultural approaches to developing well-being indicators in Solomon Islands. Ecology and Society 23 (1):32. http://dx.doi.org/10.5751/ES-09867-230132

McKinnon, M. C., S. H. Chen, S. Dupre, J. Edmond, R. Garside, L. Glew, M. B. Holland, E. Levine, Y. J. Masuda, D. C. Miller, et al. 2016. What are the effects of nature conservation on human well-being? A systemic map of empirical evidence from developing countries. Environmental Evidence 5:8. http://dx.doi. org/10.1186/s13750-016-0058-7

McShane, T. O., P. D. Hirsch, T. C. Trung, A. N. Songorwa, A. Kinzing, B. Monteferri, D. Mutekanga, H. Van Thang, J. L. Dammert, M. Pulgar-Vidal, M. Welch-Devine, J. P. Brosius, P. Coppolillo, and S. O'Connor. 2011. Hard choices: making tradeoffs between biodiversity conservation and human well-being. Biological Conservation 144:966-972. http://dx.doi.org/10.1016/j. biocon.2010.04.038

Millennium Ecosystem Assessment. 2005. Ecosystems and human well-being: biodiversity synthesis. World Resources Institute, Washington, D.C., USA.

Newmark, W. D., and J. L. Hough. 2000. Conserving wildlife in Africa: integrated conservation and development projects and beyond. BioScience 50:585-592. http://dx.doi.org/10.1641/0006-3568 (2000)050[0585:CWIAIC]2.0.CO;2

Pascual, U., J. Phelps, E. Garmendia, K. Brown, E. Corbera, A. Martin, E. Gomez-Baggethun, and R. Muradian. 2014. Social equity matters in payments for ecosystem services. BioScience 64 (11):1027-1036. http://dx.doi.org/10.1093/biosci/biu146

Rodriguez, I. 2017. Linking well-being with cultural revitalization for greater cognitive justice in conservation: lessons from Venezuela in Canaima National Park. Ecology and Society 22 (4):24. http://dx.doi.org/10.5751/ES-09758-220424

Smith. L. M., J. L. Case, H. M. Smith, L. C. Harwell, and J. K. Summers. 2013. Relating ecosystem services to domains of human well-being: foundation for a U.S. index. Ecological Indicators 28:79-90. http://dx.doi.org/10.1016/j.ecolind.2012.02.032

Wali, A., D. Alvira, P. S. Tallman, A. Ravikumar, and M. O. Macedo. 2017. A new approach to conservation: using community empowerment for sustainable well-being. Ecology and Society 22(4):6. http://dx.doi.org/10.5751/ES-09598-220406

West, P., J. Igoe, and D. Brockington. 2006. Parks and peoples: the social impact of protected areas. Annual Review of Anthropology 35:251-277. http://dx.doi.org/10.1146/annurev. anthro.35.081705.123308
Woodhouse, E., and J. T. McCabe. 2018. Well-being and conservation: diversity and change in visions of a good life among the Maasai of northern Tanzania. Ecology and Society 23(1):43. http://dx.doi.org/10.5751/ES-09986-230143

Zafra-Calvo, N., U. Pascual, D. Brockington, B. Coolsaet, J. A. Cortes-Vasquez, N. Gross-Camp, I. Palomo, and N. D. Burgess. 2017. Towards an indicator system to assess equitable management in protected areas. Biological Conservation 211:134-141. http://dx.doi.org/10.1016/j.biocon.2017.05.014 